\title{
Botulinum toxin A improves neurogenic bladder fibrosis by suppressing transforming growth factor $\beta 1$ expression in rats
}

\author{
Chunsong Jia, Tianying Xing, Zhenhua Shang, Xin Cui, Qi Wang, Tongwen Ou \\ Department of Urology, Xuanwu Hospital Capital Medical University, National Clinical Research Center for Geriatric Diseases, Beijing, China \\ Contributions: (I) Conception and design: C Jia, T Ou; (II) Administrative support: T Ou; (III) Provision of study materials or patients: C Jia; \\ (IV) Collection and assembly of data: C Jia, T Xing, Z Shang, Q Wang; (V) Data analysis and interpretation: C Jia, X Cui; (VI) Manuscript writing: \\ All authors; (VII) Final approval of manuscript: All authors. \\ Correspondence to: Tongwen Ou, MD, PhD. Department of Urology, Xuanwu Hospital Capital Medical University, National Clinical Research Center \\ for Geriatric Diseases, No. 45 Changchun Road, Xicheng District, Beijing 100053, China. Email: outongwen@xwhosp.org.
}

\begin{abstract}
Background: Intradetrusor botulinum toxin A injection is recommended for the treatment of refractory detrusor overactivity (DO) in patients with neurogenic bladder, however, whether it could inhibit neurogenic bladder fibrosis is uncertain. This study aimed to investigate the effect of botulinum toxin A on neurogenic bladder fibrosis and the underlying mechanism.

Methods: Forty eight Female Wistar rats were evenly randomized into 4 groups: Sham, T10 transection, Early and Late groups. The last three groups were subjected to T10 spinal cord transection, while the Sham group was treated with sham surgery. $0.9 \%$ saline was injected into the detrusor in the Sham and T10 transection groups simultaneously with the surgery, while $2 \mathrm{U} /$ rat botulinum toxin A was injected into the detrusor simultaneously with the surgery in the Early group and 4 weeks following the surgery in the Late group. Body/bladder weight, cystometric parameters, bladder Hematoxylin-eosin staining were used to evaluate the bladder fibrosis. Western blot and quantitative Real-time PCR were used to evaluate the expression of bladder transforming growth factor $\beta 1$.

Results: Compared with the T10 transection group, the bladder/body weight was decreased significantly in the Early and Late groups $(\mathrm{P}<0.05)$, along with the significant inhibition of non-voiding contraction (NVC) frequency and amplitude $(\mathrm{P}<0.05)$, and the significant increase of bladder volume $(\mathrm{P}<0.05)$. The detrusor connective tissue percentage $(\mathrm{P}<0.05)$ and the expression of transforming growth factor $\beta 1(\mathrm{P}<0.05)$ also decreased significantly in the Early and Late groups. Those changes were more obviously in the Early group than in the Late group.

Conclusions: Intradetrusor botulinum toxin A injection reduced bladder fibrosis in rats with spinal cord injury (SCI), which was more obviously in the Early group than in the Late group. The mechanisms might be mediated by suppression of transforming growth factor $\beta 1$ (TGF- $\beta 1$ ) expression.
\end{abstract}

Keywords: Spinal cord injury (SCI); neurogenic bladder; bladder fibrosis; botulinum toxin A; transforming growth factor $\beta 1$ (TGF- $\beta 1)$

Submitted Jan 22, 2021. Accepted for publication Apr 04, 2021.

doi: 10.21037/tau-21-62

View this article at: http://dx.doi.org/10.21037/tau-21-62

\section{Introduction}

Supraspinal cord injury usually induces detrusor overactivity (DO), detrusor-sphincter dyssynergia and bladder fibrosis, resulting urinary dysfunction, such as urgency, frequency, incontinence, retention, and renal impairment in some cases (1).
Intradetrusor botulinum toxin A (BoNTA) injection is a safe, cost-effective and long-term therapy for patients with neurogenic DO $(1,2)$. However, few studies have explored the effect of intradetrusor BoNTA injection on neurogenic bladder fibrosis and the answer remains unclear. In patients 
with neurogenic DO, BoNTA injection did not increase extracellular matrix or collagen deposition (3-5), but repeated injections reduced bladder fibrosis (6). In rats with spinal cord injury (SCI), BoNTA injection decreased bladder fibrosis with short-term and small-scale observation (7). Transforming growth factor $\beta 1$ (TGF- $\beta 1$ ) is a key cytokine in promoting fibrosis (8), but few studies explored the relationship between BoNTA injection and TGF- $\beta 1$ expression in the treatment of neurogenic bladder. The study aimed to explore the effect of intradetrusor BoNTA injection on bladder fibrosis and TGF- $\beta 1$ expression in rats with T10 spinal cord transection. As fibrosis is usually irreversible, we divided the rats received BoNTA injection into the Early group and the Late group to further explore the benefit of early application of BoNTA on bladder fibrosis in this study.

We present the following article in accordance with the ARRIVE reporting checklist (available at http://dx.doi. org/10.21037/tau-21-62).

\section{Methods}

\section{Rat models}

This study was performed in compliance with the National Institute of Health Guidelines for the Care and Use of Laboratory Animals and approved by the Institutional Animal Care and Use Committee of Xuanwu Hospital Capital Medical University (No. 20190128). Forty eight female Wistar rats $(200 \pm 10 \mathrm{~g})$ were obtained from Beijing Vital River Laboratory Animal Technology Co., Ltd. (Beijing, China) and randomly divided into four groups $(\mathrm{n}=12$, respectively): Sham, T10 transection, Early and Late. The Sham group underwent T10 sham operation, which opened the spinal canal and the dura mater, but did not damage the spinal cord and then closed the wound. The other three groups underwent T10 spinal cord transection. For intradetrusor injection, agents (totally $80 \mu \mathrm{L}$ ) were injected into four sites around the bladder base and four sites around the middle of the bladder between the serosal layer and the muscle layer via a midline abdominal incision using a syringe needle (30G). A total of $0.9 \%$ saline was injected into the detrusor in the Sham and T10 transection groups simultaneously with the surgery, while $2 \mathrm{U} / \mathrm{rat}$ BoNTA (Hengli ${ }^{\circledR}$, Lanzhou Biological Products, China) was injected into the detrusor simultaneously with the surgery in the Early group and 4 weeks following the surgery in the Late group. T10 spinal cord transection and intradetrusor injection were made under $2 \%$ isoflurane anesthesia. After operation, rats were kept alone and provided free access to food and water. The bladders were urinated manually 3 times a day for 14 days and then once a day.

\section{Cystometry in conscious rats}

Conscious cystometry was recorded following the measurement of body weight in all rats by 8 weeks post spinalization. First, the bladder dome was exposed via a midline abdominal incision and the ureters were ligated at the level of the aortic bifurcation under $2 \%$ isoflurane anesthesia, then, cystometric parameters was recorded according to previous report after two stable micturition cycles at an infusing speed of $0.08 \mathrm{~mL} / \mathrm{min}$ with $0.9 \%$ saline after the rats recovered from anesthesia for $1 \mathrm{~h}$. Cystometric parameters included bladder volume, non-voiding contraction (NVC) frequency and NVC amplitude (9). Bladder volume was defined as the infusion volume when the fluid releases from urethra, and NVCs were defined as rhythmic intravesical pressure increases over $7 \mathrm{cmH}_{2} \mathrm{O}$ from baseline pressure without release of fluid from the urethra (9). After cystometry, the rats were sacrificed and the bladders were weighed after removal and divided into 4 pieces via the sagittal and coronal planes. Three pieces of the detrusor were separated and used for Western blot and quantitative realtime polymerase chain reaction (qRT-PCR) analysis, while one piece was used for paraffin embedding.

\section{Evaluation of detrusor fibrosis with hematoxylin-eosin (HE) staining}

HE staining and Masson staining were performed with $4 \mu \mathrm{m}$ sections of bladder strips after dewaxing and rehydration. The sections were scanned with APERIO AT TURBO slide scanning system (Aperio Technologies, USA) at $20 \times$ magnification and saved as digital images. Three areas of muscle layer were randomly selected for evaluation at $10 \times$ magnification and saved as JPG files. The abundance of connective tissue in the HE staining were evaluated with Fiji-win64: connective tissue percentage $(\%)=$ connective tissue area/detrusor area $\times 100$. The experiments were done using randomized blind selection.

\section{Evaluation of TGF-ß1 protein expression with Western blot}

The supernatant of homogenized detrusor was separated with $12.5 \%$ sodium dodecyl sulfate-polyacrylamide gel electrophoresis and transferred to PVDF membrane. 
Table 1 Changes of bladder weight and bladder function ( $\mathrm{n}=12$ each group)

\begin{tabular}{lcccc}
\hline Variables & Sham & T10 transection & Early & Late \\
\hline Body weight $(\mathrm{g})$ & $272 \pm 12$ & $264 \pm 13$ & $267 \pm 8$ & $258 \pm 15^{\star}$ \\
Bladder weight $(\mathrm{g})$ & $0.2 \pm 0.1$ & $0.6 \pm 0.1^{*}$ & $0.4 \pm 0.1^{* \&}$ & $0.5 \pm 0.1^{* \&}$ \\
Bladder/body weight $\left(\times 10^{4}\right)$ & $9.1 \pm 2.3$ & $24.0 \pm 5.2^{*}$ & $14.3 \pm 4.1^{* \&}$ & $18.5 \pm 2.9^{* \text { \& }}$ \\
\hline
\end{tabular}

*, $\mathrm{P}<0.01$ compared with Sham; ${ }^{*}, \mathrm{P}<0.05$ compared with $\mathrm{T} 10$ transection; ${ }^{\text {}}, \mathrm{P}<0.05$ compared with Early.

The membrane was incubated with rabbit anti-TGF- $\beta 1$ monoclonal antibody (1:5,000; Abcam, Shanghai, China) and mouse anti-GAPDH monoclonal antibody $(1: 1,000$; ZSGB Biotechnology, Beijing, China) at $4{ }^{\circ} \mathrm{C}$ overnight, and then with HRP-conjugated goat anti-rabbit IgG (1:500; ZSGB Biotechnology, Beijing, China) and HRP-conjugated goat anti-mouse IgG (1:4,000; ZSGB Biotechnology, Beijing, China) at room temperature for $1 \mathrm{~h}$. Immunoreactive bands were visualized using an enhanced chemiluminescence system. The relative TGF- $\beta 1$ expression was normalized to GAPDH. Each experiment was performed in triplicate.

\section{Evaluation of TGF- 1 mRNA expression with quantitative real-time PCR}

Total RNA was extracted from homogenized detrusor with the TRIzol reagent (Invitrogen, Grand Island, NY, USA) and synthesized to cDNA with the Prime-Script RT reagent kit (TaKaRa, Dalian, China). Roche LightCycler ${ }^{\circledR} 480$ instrument II (Roche Diagnostics Ltd., Shanghai, China) was used for qRT-PCR. The primers were as following: GCTGAAGCCGTTCATTTAGC (forward) and GAGGAGGCCAAATTCAACAA (reverse) for TGF- $\beta 1$; ACAAGATGGTGAAGGTCGGTG (forward) and AGAAGGCAGCCCTGGTAACC (reverse) for GAPDH. The reaction system was as following: $1 \mu \mathrm{L}$ cDNA (10 ng), $2 \mu \mathrm{L} 10 \times$ Ex Taq Buffer (TaKaRa, Dalian, China), $1 \mu \mathrm{L}$ dNTP Mixture (TaKaRa, Dalian, China), $0.2 \mu \mathrm{L}$ Ex Taq ${ }^{\circledR}$ Hot Start Version (TaKaRa, Dalian, China), $2 \mu \mathrm{L} \mathrm{SYBR}$ Green I (BioTek, Beijing, China), $1 \mu \mathrm{L}(10 \mu \mathrm{M})$ forward primer, $1 \mu \mathrm{L}(10 \mu \mathrm{M})$ reverse primer and $11.8 \mu \mathrm{L}$ DEPCtreated water. The temperature program encompassed $95^{\circ} \mathrm{C}$ for $2 \mathrm{~min}, 95^{\circ} \mathrm{C}$ for $10 \mathrm{~s}$, and 40 cycles of $60^{\circ} \mathrm{C}$ for $40 \mathrm{~s}$, and $72{ }^{\circ} \mathrm{C}$ for $30 \mathrm{~s}$. TGF- $\beta 1 \mathrm{mRNA}$ expression was normalized to GAPDH. Each experiment was performed in triplicate.

\section{Statistical analysis}

Data are expressed as means \pm SD. One-way ANOVA with
LSD or Dunnett's test was used for comparisons between groups. SPSS 22.0 software (IBM, Armonk, NY, USA) was used for data analysis and differences with $\mathrm{P}<0.05$ were considered statistically significant.

\section{Results}

\section{Changes of bladder/body weight}

There was no significant difference about body weight between the four groups, except for the Sham group and the Late group $(\mathrm{P}<0.01)$ (Table 1). The bladder weight in the SCI rats was increased significantly compared with the Sham group $(\mathrm{P}<0.01)$, meanwhile, it was intermediate between the Sham group and the T10 transection group in the two BoNTA-treated groups (Table 1). The bladder/ body weight ratios were in line with the changes of bladder weight among the groups. Notably, it decreased significantly in the Early group compared with the Late group $(\mathrm{P}<0.05$; Table 1).

\section{Changes of cystometric parameters}

The NVC frequency increased significantly in the SCI rats compared with the Sham group $(\mathrm{P}<0.05)$, meanwhile, it was intermediate between the Sham group and the T10 transection group in the two BoNTA-treated groups (Table 2, Figure 1). Notably, the NVC frequency decreased significantly in the Early group compared with the Late group $(\mathrm{P}<0.05)$ (Table 2, Figure 1). The NVC amplitude had the similar tendency to the changes of NVC frequency, however, there was no significant difference between the Early and Late groups $(\mathrm{P}=0.053$; Table 2, Figure 1). The bladder volume had the opposite tendency to the changes of NVC frequency among the groups (Table 2, Figure 1).

\section{Changes of bladder fibrosis}

The detrusor connective tissue percentage increased 
Table 2 Changes of bladder function ( $\mathrm{n}=12$ each group)

\begin{tabular}{lcccc}
\hline Variables & Sham & T10 transection & Early & Late \\
\hline DO frequency $(\mathrm{n})$ & $5.1 \pm 1.7$ & $17.1 \pm 2.6^{\star}$ & $9.6 \pm 1.8^{\star \&}$ & $13.4 \pm 2.9^{\star \& \sharp}$ \\
DO amplitude $\left(\mathrm{cmH}_{2} \mathrm{O}\right)$ & $8.1 \pm 0.8$ & $16.9 \pm 3.0^{*}$ & $10.0 \pm 1.7^{\star \&}$ & $12.8 \pm 2.8^{\star \&}$ \\
Bladder volume $(\mathrm{mL})$ & $2.0 \pm 0.2$ & $1.0 \pm 0.3^{*}$ & $1.6 \pm 0.4^{\star \&}$ & $1.3 \pm 0.3^{\star \& \&}$ \\
\hline
\end{tabular}

${ }^{*}, \mathrm{P}<0.05$ compared with Sham; ${ }^{\circ}, \mathrm{P}<0.05$ compared with T10 transection;, , P $<0.05$ compared with Early. DO, detrusor overactivity.

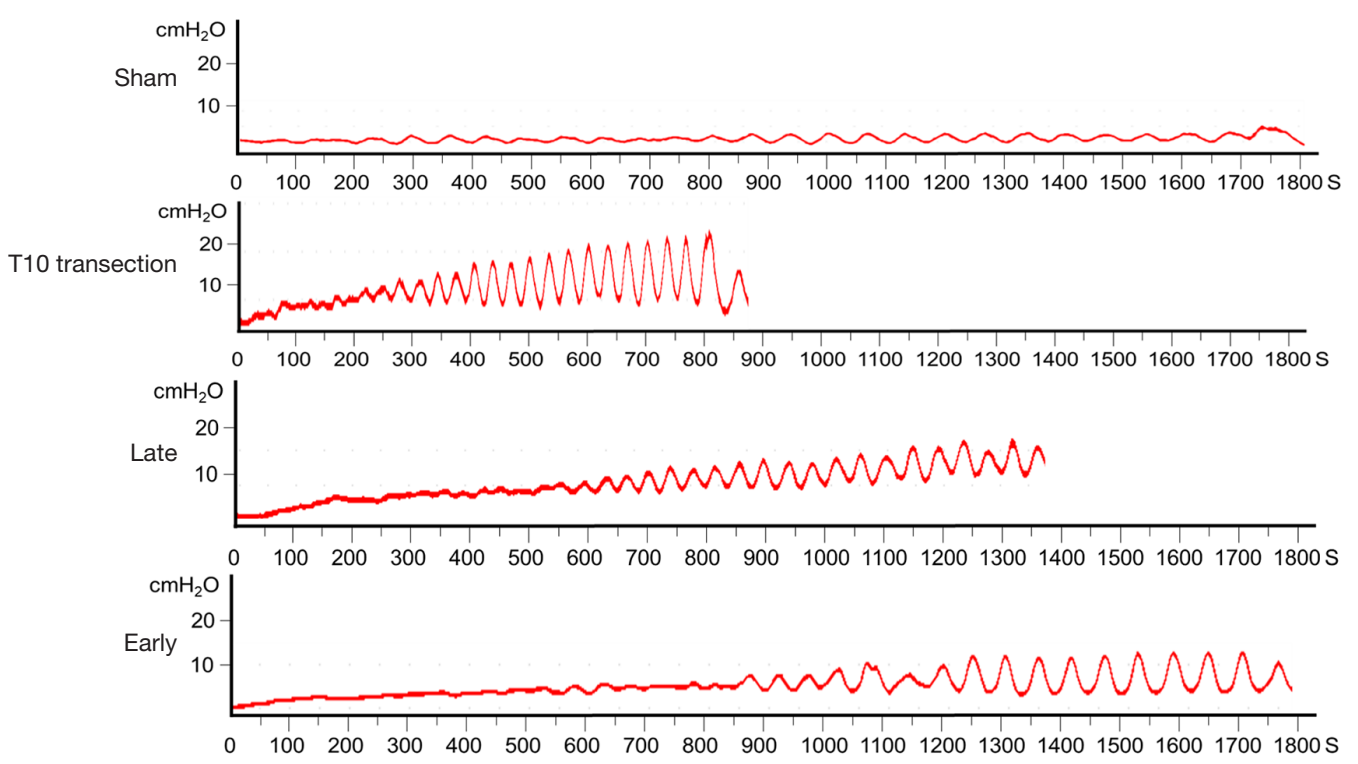

Figure 1 Representative traces of bladder cystometry.

significantly in the SCI rats compared with the Sham group $(\mathrm{P}<0.05)$, meanwhile, it was intermediate between the Sham group and the T10 transection group in the two BoNTA-treated groups (Figure 2). Notably, the detrusor connective tissue percentage was tended to decrease in the Early group compared with the Late group $(\mathrm{P}=0.133$; Figure 2).

\section{Changes of TGF- $\beta 1$ expression}

TGF- $\beta 1$ protein expression increased significantly in the SCI rats compared with the Sham group $(\mathrm{P}<0.05)$, meanwhile, it was intermediate between the Sham group and the T10 transection group in the two BoNTA-treated groups (Figure 3). Notably, TGF- $\beta 1$ protein decreased significantly in the Early group compared with the Late group $(\mathrm{P}<0.05)$ (Figure 3$)$. TGF- $\beta 1 \mathrm{mRNA}$ was in line with the changes of TGF- $\beta 1$ protein expression among the groups (Figure 3).

\section{Discussion}

The prevalence of SCI is as high as 236-1,298/1 million in the world (10), and as many as $95 \%$ patients suffer from neurogenic bladder, but less than $1 \%$ patients' bladder function could fully recover when discharged from hospital (11). The improvement of DO and bladder fibrosis could reduce detrusor pressure and increase bladder volume, thus improving urinary dysfunction, reducing the risk of hydronephrosis and protecting renal function in SCI patients (12).

In patients with neurogenic DO refractory to anticholinergics/antimuscarinics, BoNTA injection should be considered as the next step to restore a low pressure, highcapacity reservoir (12). A dose of $300 \mathrm{U}^{\mathrm{Hengli}}{ }^{\circledR}$ BoNTA is usually used for the treatment of DO in patients with supraspinal cord transection, which is approximately $5 \mathrm{U} / \mathrm{kg}$. This dose was considered to correspond to $1 \mathrm{U} / \mathrm{rat}$ in this study. The fibrosis-inhibiting effect was evaluated by some arbitrarily comparing with $2 \mathrm{U} / \mathrm{rat}$ of BoNTA. Previous 
A

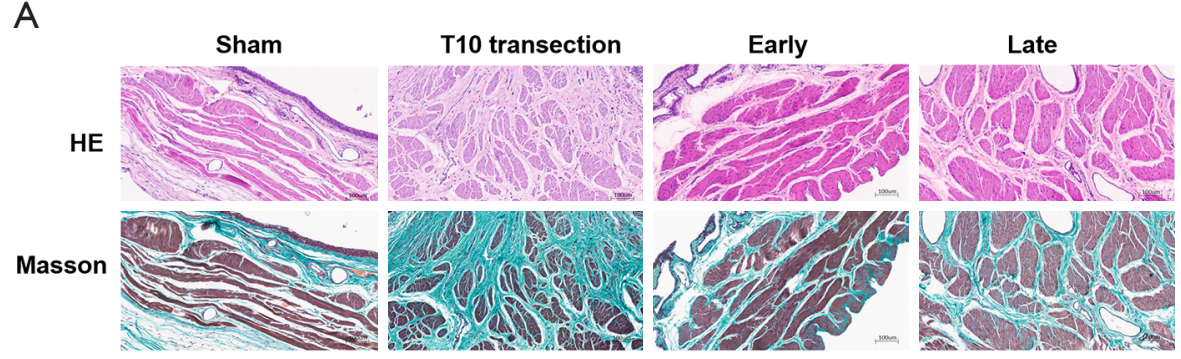

B

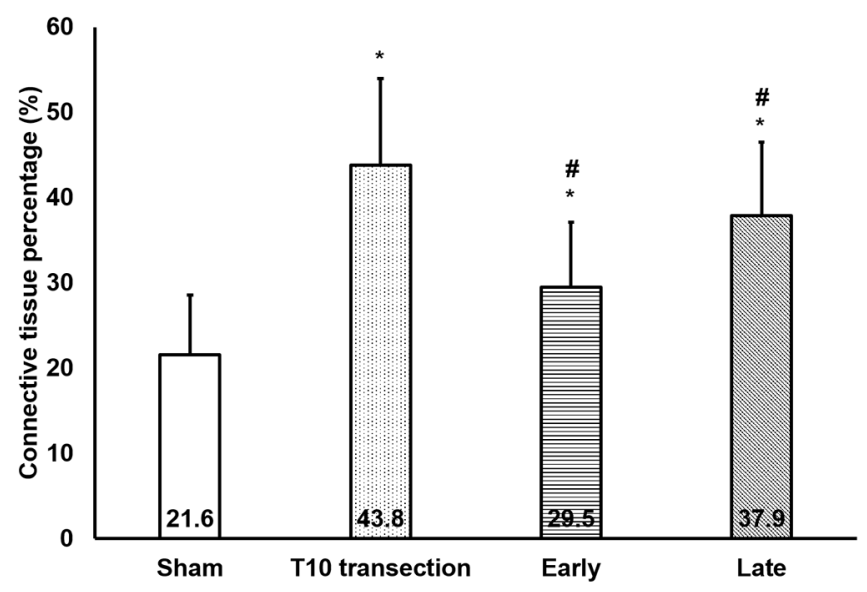

Figure 2 Changes of detrusor fibrosis ( $\mathrm{n}=12$, respectively). (A) Bladder HE and Masson staining; (B) changes of detrusor connective tissue percentage. *, $\mathrm{P}<0.05$ compared with Sham; ${ }^{,}, \mathrm{P}<0.01$ compared with $\mathrm{T} 10$ transection. Scale bar $=100 \mu \mathrm{m}$.

studies on bladder injection used BoNTA doses ranging from $1-5 \mathrm{U} / \mathrm{rat}(7,13,14)$. The BoNTA used in our research is the same serotype A of botulinum toxin as those used in previous studies $(7,13,14)$, but the manufacturers are different.

To clarify whether intradetrusor BoNTA injection could prevent bladder fibrosis makes sense to the usage of BoNTA in patients with supraspinal cord injury. Histologically, bladder fibrosis is characterized by excessive deposition of connective tissue between and within the detrusor muscle bundles (15-17), usually accompanied by hypertrophy/ hyperplasia of detrusor muscle cells, increased bladder weight and disordered bladder function (18). In this study, we found the inhibited NVCs, increased bladder volume, decreased detrusor connective tissue deposition and bladder weight following BoNTA injection, which implies BoNTA injection is effective to inhibit bladder fibrosis caused by supraspinal cord injury. Neurogenic bladder fibrosis in those patients is usually irreversible, and early BoNTA injection might prevent the fibrosis. Previous study showed BoNTA injection decreased bladder fibrosis in SCI rats independent of the time interval between SCI and BoNTA treatment (7). However, we found that the bladder/body weight, DO frequency and bladder volume improved significantly in the Early group than in the Late group, while there was no significant difference between them in the bladder weight, DO amplitude and connective tissue percentage. Thus, this study showed early BoNTA injection had a tendency to prevent bladder fibrosis, but further research is needed to provide a definite answer.

It was proposed that the action of BoNTA on neurogenic bladder fibrosis is through reducing detrusor contractility by inhibiting the release of acetylcholine from presynaptic nerve terminals (7). However, TGF- $\beta 1$ might play an important role in this process. TGF- $\beta 1$ is a major driver of human fibrotic pathologies, including hepatic, renal, cardiac and pulmonary fibrosis (19), which induces collagen production and fibrocyte-myofibroblast differentiation through binding to serine/threonine kinase receptors on the cell surface that phosphorylates intracellular Smad2/3 transcription factors (20). Reports showed that BoNTA 

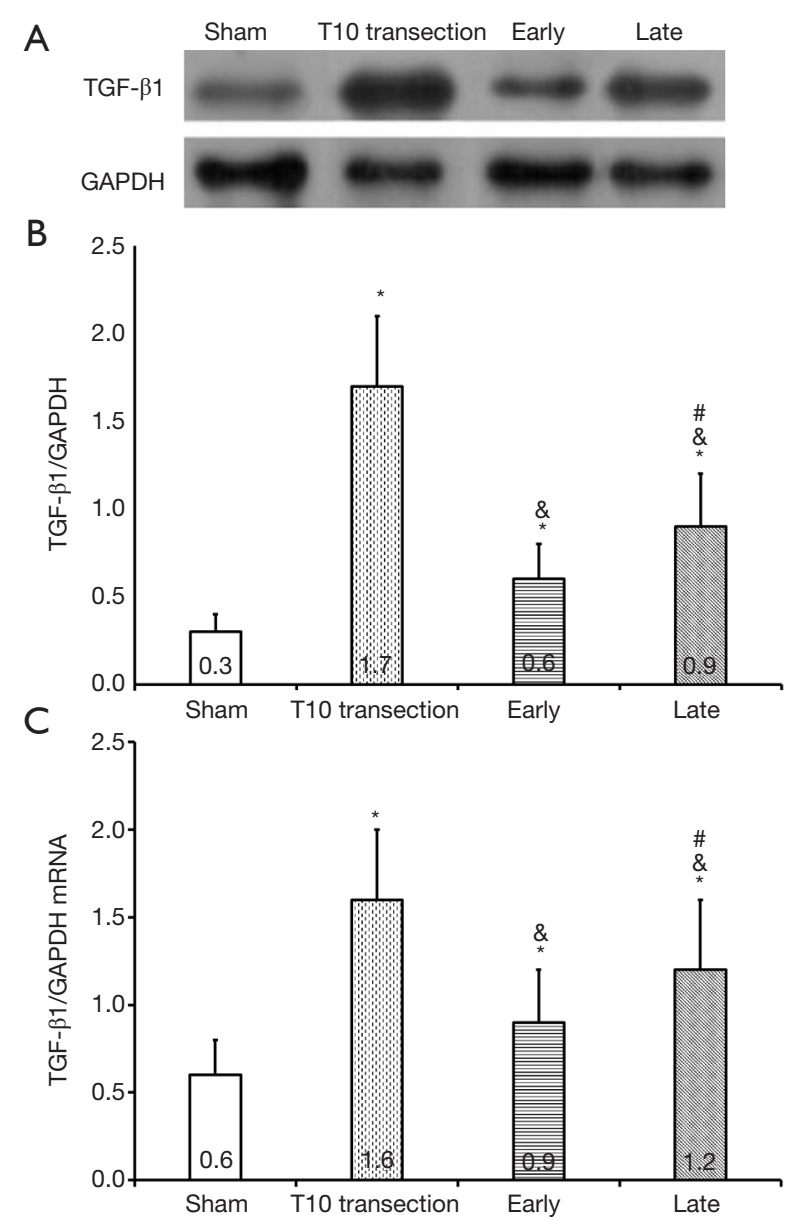

Figure 3 Changes of detrusor TGF- $\beta 1$ expression in rats with BoNTA treatment ( $\mathrm{n}=12$, respectively). TGF- $\beta 1$ expression was examined with Western blot (A and B) and qRT-PCR (C). *, $\mathrm{P}<0.05$ compared with Sham; ${ }^{\&}, \mathrm{P}<0.05$ compared with T10 transection; ${ }^{\#}, \mathrm{P}<0.05$ compared with Early. TGF- $\beta 1$, transforming growth factor $\beta 1$.

could reduce the expression of TGF- $\beta 1$ in fibroblasts derived from hypertrophic scars in vitro (21-23). Our study showed that TGF- $\beta 1$ expression was inhibited in SCI rats following BoNTA injection, which demonstrates a mechanism of BoNTA action by downregulating TGF- $\beta 1$ expression.

The main limitation of this study was the short-term observation. The bladder fibrosis progresses gradually, and DO improvement with BoNTA injection begins within 1 to 2 weeks of injection and lasts for 9 to 10 months in patients with neurogenic bladder (24), thus, 8 weeks might be too short to evaluate the agent's effect.

\section{Conclusions}

Bladder fibrosis aggravates urinary dysfunction and endangers kidney function in patients with suprasacral SCI. However, there is currently no effective treatment. Our research showed that the bladder fibrosis and TGF- $\beta 1$ expression could be suppressed by intradetrusor BoNTA injection in SCI rats. The results suggest the usage of BoNTA to prevent bladder fibrosis in SCI patients with DO and demonstrate a mechanism of BoNTA action by downregulating TGF- $\beta 1$ expression.

\section{Acknowledgments}

Funding: This work was supported by the National Natural Science Foundation of China [grant numbers: 81500578; 82070787] and Beijing Municipal Administration of Hospitals Clinical Medicine Development of special Funding Support [grant number: ZYLX201801].

\section{Footnote}

Reporting Checklist: The authors have completed the ARRIVE reporting checklist. Available at http://dx.doi. org/10.21037/tau-21-62

Data Sharing Statement: Available at http://dx.doi. org/10.21037/tau-21-62

Peer Review File: Available at http://dx.doi.org/10.21037/ tau-21-62

Conflicts of Interest: All authors have completed the ICMJE uniform disclosure form (available at http://dx.doi. org/10.21037/tau-21-62). All authors report grants from National Natural Science Foundation of China [grant numbers: 81500578; 82070787], grants from Beijing Municipal Administration of Hospitals Clinical Medicine Development of special Funding Support [grant number: ZYLX201801], during the conduct of the study.

Ethical Statement: The authors are accountable for all aspects of the work in ensuring that questions related to the accuracy or integrity of any part of the work are appropriately investigated and resolved. All experimental procedures were implemented in compliance with the National Institute of Health Guidelines for the Care 
and Use of Laboratory Animals and approved by the Institutional Animal Care and Use Committee of Xuanwu Hospital Capital Medical University (No. 20190128).

Open Access Statement: This is an Open Access article distributed in accordance with the Creative Commons Attribution-NonCommercial-NoDerivs 4.0 International License (CC BY-NC-ND 4.0), which permits the noncommercial replication and distribution of the article with the strict proviso that no changes or edits are made and the original work is properly cited (including links to both the formal publication through the relevant DOI and the license). See: https://creativecommons.org/licenses/by-nc-nd/4.0/.

\section{References}

1. Kavanagh A, Baverstock R, Campeau L, et al. Canadian Urological Association guideline: Diagnosis, management, and surveillance of neurogenic lower urinary tract dysfunction - Executive summary. Can Urol Assoc J 2019;13:156-65.

2. Cooley LF, Kielb S. A Review of Botulinum Toxin A for the Treatment of Neurogenic Bladder. PM R 2019;11:192-200.

3. Pascali MP, Mosiello G, Boldrini R, et al. Effects of botulinum toxin type a in the bladder wall of children with neurogenic bladder dysfunction: a comparison of histological features before and after injections. J Urol 2011;185:2552-7.

4. Haferkamp A, Schurch B, Reitz A, et al. Lack of ultrastructural detrusor changes following endoscopic injection of botulinum toxin type a in overactive neurogenic bladder. Eur Urol 2004;46:784-91.

5. Apostolidis A, Jacques TS, Freeman A, et al. Histological changes in the urothelium and suburothelium of human overactive bladder following intradetrusor injections of botulinum neurotoxin type A for the treatment of neurogenic or idiopathic detrusor overactivity. Eur Urol 2008;53:1245-53.

6. Compérat E, Reitz A, Delcourt A, et al. Histologic features in the urinary bladder wall affected from neurogenic overactivity--a comparison of inflammation, oedema and fibrosis with and without injection of botulinum toxin type A. Eur Urol 2006;50:1058-64.

7. Temeltas G, Tikiz C, Dagci T, et al. The effects of botulinum-A toxin on bladder function and histology in spinal cord injured rats: is there any difference between early and late application? J Urol 2005;174:2393-6.
8. Lijnen P, Petrov V, Rumilla K, Fagard R. Transforming growth factor-beta 1 promotes contraction of collagen gel by cardiac fibroblasts through their differentiation into myofibroblasts. Methods Find Exp Clin Pharmacol 2003;25:79-86.

9. Jia C, Yoshimura N, Liao L. Herpes simplex virus vectormediated gene transfer of kynurenine aminotransferase improves detrusor overactivity in spinal cord-injured rats. Gene Ther 2014;21:484-9.

10. Furlan JC, Sakakibara BM, Miller WC, et al. Global incidence and prevalence of traumatic spinal cord injury. Can J Neurol Sci 2013;40:456-64.

11. Przydacz M, Chlosta P, Corcos J. Recommendations for urological follow-up of patients with neurogenic bladder secondary to spinal cord injury. Int Urol Nephrol 2018;50:1005-16.

12. Stein R, Bogaert G, Dogan HS, et al. EAU/ESPU guidelines on the management of neurogenic bladder in children and adolescent part II operative management. Neurourol Urodyn 2020;39:498-506.

13. Tinay I, Tanidir Y, Cikler E, et al. Intradetrusor botulinum neurotoxin A (BoNT-A) injections decrease bladder fibrosis secondary to partial urethral obstruction in the male rat model. Neurourol Urodyn 2012;31:564-70.

14. Ha US, Park EY, Kim JC. Effect of botulinum toxin on expression of nerve growth factor and transient receptor potential vanilloid 1 in urothelium and detrusor muscle of rats with bladder outlet obstruction-induced detrusor overactivity. Urology 2011;78:721.e1-721.e6.

15. Deveaud CM, Macarak EJ, Kucich U, et al. Molecular analysis of collagens in bladder fibrosis. J Urol 1998;160:1518-27.

16. Howard PS, Renfrow D, Schechter NM, Kucich U. Mast cell chymase is a possible mediator of neurogenic bladder fibrosis. Neurourol Urodyn 2004;23:374-82.

17. Fry CH, Kitney DG, Paniker J, et al. Fibrosis and the bladder, implications for function ICI-RS 2017. Neurourol Urodyn 2018;37:S7-S12.

18. Duan LJ, Qi J, Kong XJ, et al. MiR-133 modulates TGFbeta1-induced bladder smooth muscle cell hypertrophic and fibrotic response: implication for a role of microRNA in bladder wall remodeling caused by bladder outlet obstruction. Cell Signal 2015;27:215-27.

19. Walton KL, Johnson KE, Harrison CA. Targeting TGFbeta Mediated SMAD Signaling for the Prevention of Fibrosis. Front Pharmacol 2017;8:461.

20. Fuschiotti $P$, Larregina AT, Ho J, et al. Interleukin13-producing CD8+ T cells mediate dermal fibrosis 
in patients with systemic sclerosis. Arthritis Rheum 2013;65:236-46.

21. Reid RR, Roy N, Mogford JE, et al. Reduction of hypertrophic scar via retroviral delivery of a dominant negative TGF-beta receptor II. J Plast Reconstr Aesthet Surg 2007;60:64-72.

22. Lu L, Saulis AS, Liu WR, et al. The temporal effects of anti-TGF-beta1, 2, and 3 monoclonal antibody on wound healing and hypertrophic scar formation. J Am Coll Surg 2005;201:391-7.

23. Xiao Z, Zhang F, Lin W, et al. Effect of botulinum toxin type A on transforming growth factor betal in fibroblasts derived from hypertrophic scar: a preliminary report. Aesthetic Plast Surg 2010;34:424-7.

24. Smith CP, Chancellor MB. Botulinum Toxin to Treat Neurogenic Bladder. Semin Neurol 2016;36:5-9.
Cite this article as: Jia C, Xing T, Shang Z, Cui X, Wang Q, Ou T. Botulinum toxin A improves neurogenic bladder fibrosis by suppressing transforming growth factor $\beta 1$ expression in rats. Transl Androl Urol 2021;10(5):2000-2007. doi: 10.21037/tau-21-62 